\title{
Música, redes e tecnologia na periferia: impactos tecnológicos na produção de rap na zona sul de São Paulo
}

Music, networks and technology in urban outskirts: technological impacts on rap production at south of São Paulo

\begin{abstract}
The ICT technological paradigm brought significant changes in the economics of music, reducing costs and expanding possibilities production access. The objective of the present work is to verify if the current technological impacts on the music production are also perceived in urban peripheral zones, starting from the case study of the production of rap music in Grajaú, district of São Paulo, Brazil. Thus, the hypothesis is considered: the technological impacts reduced production costs and increased access to music production. In addition, new organizational production forms emerged, based on networks. The results are summarized as follows: a) the impacts of ICTs on music production are verified in the specific case study, suggesting that innovations also reach the periphery; b) the local music production occurs in organizations based on networks, incorporating monetary and community relations. It is noted that the rap music production in Grajaú presents community and collaborative aspects associated with economic and monetary.
\end{abstract}

\section{Keywords}

creative economy, economics of music, social networks, technological innovations.

JEL Codes Z11, L82.

\author{
Rodrigo Cavalcante Michel (1) \\ Ana Flávia Machado (2) \\ Natália Guimarães Duarte Sátyro(3) \\ (1) Universidade Federal de Minas Gerais \\ (2) Universidade Federal de Minas Gerais \\ (3) Universidade Federal de Minas Gerais
}

\section{Resumo}

O paradigma tecnológico das TICS trouxe mudanças significativas na economia da música, reduzindo custos e ampliando possibilidades de acesso à produção. O objetivo do presente artigo é verificar se os atuais impactos tecnológicos na produção de música também são percebidos em zonas periféricas urbanas, a partir do estudo de caso da produção de música rap no Grajaú. Assim, considera-se a hipótese: os impactos tecnológicos possibilitaram redução nos custos de produção e ampliação do acesso à produção musical. Ademais, novas formas organizacionais de produção emergem baseadas em redes. Os resultados encontrados resumem-se em: a) os impactos das TICs na produção musical verificam-se no estudo de caso específico, sugerindo que as inovações atingem também a periferia; b) a produção de música local ocorre em organizações baseadas em redes, incorporando relações monetárias e comunitárias. Nota-se que a produção de música rap no Grajaú apresenta aspectos comunitários e colaborativos associados a econômicos e monetários.

\section{Palavras-chave}

economia criativa, economia da música, redes, inovações tecnológicas.

Códigos JEL Z11, L82. 


\section{Introdução}

O setor de produção musical passa recorrentemente por transformações tecnológicas que modificam a forma produtiva, a estrutura de mercado, a atuação dos agentes, o formato do produto e, consequentemente, a forma do consumo. Atualmente, o setor se encontra na onda tecnológica das Tecnologias de Informação e Comunicação (doravante, TICs), com intenso uso de fatores digitais e cibernéticos. A digitalização da música nos anos 2000 trouxe mudanças no que tange ao processo de produção, distribuição e consumo. Algumas teorias e análises acadêmicas afirmam que o atual cenário tecnológico e estrutural do setor favorece a presença de agentes de menor porte no mercado, bem como redução das barreiras à entrada. ${ }^{1}$

$\mathrm{Na}$ esteira dessa revolução tecnológica, a partir de meados da década de 1990, os processos de produção, comercialização e consumo de música sofreram modificações, pois a produção (gravação, mixagens e sonorização) foi alvo de alterações nos processos. Essas modificações se deram, também, na estrutura de custos e investimentos na produção de música, pois possibilitaram a utilização de computadores pessoais e uso de softwares livres ou facilmente adquiridos na internet. Ademais, as TICs ocasionaram ampliação de mercado e formação de novos nichos por meio da ampla difusão do uso da internet e de redes de compartilhamento de arquivos, vídeos e redes sociais (Nakano et al., 2010; Wikstrom, 2009; Dolata, 2011; Leyshon, 2014;). Nesse período, a música passou a se consolidar no formato digital, com o surgimento de novas possibilidades de consumo, bem como "trocas" e compras de música através das plataformas peer-to-peer e streaming. Além disso, as plataformas streaming ${ }^{2}$ permitem a fruição de música pelo usuário sem a necessidade de "baixar" ou comprar as músicas. Assim, empresários nessa indústria se deparam com a necessidade de uma reorganização produtiva e mercadológica (Dias, 2000; Herschmann; Kischinhevsky, 2005).

Nesse novo cenário, criam-se oportunidades para maior divulgação de músicas realizadas fora das maiores empresas, e fora dos grandes centros

1 No artigo são apresentadas referências que servem como principal arcabouço teórico e conceitual para o problema em questão. Os trabalhos de Wikstrom (2009), Dolata (2011) e Leyshon (2014) constatam o impacto das TICs no aumento da participação de entrantes no mercado musical.

2 Streaming são plataformas que transmitem música e/ou vídeo sem a necessidade de download pelo usuário, como YouTube, Spotify, Tidal, Vimeo. 
urbanos como, por exemplo, as músicas produzidas nas periferias urbanas. O horizonte de atuação também se amplia, uma vez que se torna mais fácil divulgar e consumir músicas de diversas partes do país. As TICs, ao desonerarem o processo produtivo e ampliarem o acesso à produção, revelam estilos musicais que antes eram localmente concentrados, como é o caso do tecnobrega, mangobeat, rap, entre outros. E o alargamento do mercado destes estilos se dá pela atuação de organizações de menor porte. Ao contrário das majors, ${ }^{3}$ empresas que, inicialmente, concentravam e definiam o repertório musical, as empresas indies, de produção independente, tornam-se importantes canais de produção e distribuição musical.

A partir disso, analisamos de que forma o uso da tecnologia possibilitou (e tem possibilitado) a inserção de novos atores no mercado de música, ou ainda, tem oportunizado outra forma de atuação de músicos já inseridos no mercado, através de uma análise do arranjo das relações entre os agentes nessas produções específicas. A investigação do fenômeno apresentado é realizada através da análise de um caso específico, a produção de rap na zona sul de São Paulo/SP, especificamente no distrito do Grajaú, um dos 96 distritos do município paulistano. ${ }^{4}$ Dessa forma, o presente trabalho visa contribuir com a discussão dos impactos tecnológicos na economia criativa ao discorrer acerca desses efeitos em um espaço urbano específico e periférico. Grande parte da literatura especializada advém de autores de países desenvolvidos como Estados Unidos, Austrália e Reino Unido e, por muitas vezes, não analisa disparidades regionais, sociais e econômicas que permeiam os espaços urbanos de países menos desenvolvidos. A contribuição inova também com o desenho de pesquisa e a técnica aqui empregados - análise de redes sociais - pouco utilizados nas Ciências Econômicas, mas de relevância para estudos em Economia Criativa (Ormerod et al., 2008). A pertinência da metodologia empregada começa pela junção

3 Compreende-se como majors empresas gravadoras e distribuidoras com ampla atuação no mercado, que contam em seu leque uma variedade de produtos e artistas cosolidados e com apelo de público grande. Alguns exemplos podem ser citados como, Warner, Sony, EMI etc.

4 Trata-se de um distrito bastante povoado, com crescimento populacional nos últimos anos acima da média paulistana, porém com densidade populacional baixa. A renda dos habitantes se situa em patamares baixos quando comparada com outros distritos do município. Por outro lado, o Grajaú se apresenta como um território de forte presença do rap, representando, em conjunto com outros territórios da zona sul de São Paulo, um epicentro de criatividade desse movimento. Nomes como Racionais MCs, Sabotage e Criolo são grandes expoentes do rap nacional, sendo todos originários da zona sul de São Paulo, e o último, especificamente do Grajaú. 
da técnica com uma abordagem teórica que pressupõe laços entre os atores envolvidos, e isso se reflete nos resultados alcançados, podendo assim se tornar base para trabalhos vindouros no tema.

O objetivo principal da pesquisa é, então, verificar se as mudanças tecnológicas proporcionadas pelas TICs no processo produtivo de música ocasionaram maior participação e dinamismo de agentes no mercado localizados em periferias urbanas. Além disso, propõe-se inferir sobre a organização da produção de música nesses espaços, buscando medir a natureza das relações estabelecidas entre os agentes inseridos na rede de produção analisada. Tendo-se tal objeto em tela, organizamos este artigo em cinco seções, incluindo esta introdução. Na próxima seção, tratamos do papel de redes no contexto da digitalização da música. Em seguida, na terceira seção, apresentamos a estrutura metodológica desse estudo de caso. Na quarta seção, descrevemos os resultados encontrados e, por fim, apresentamos as considerações finais.

\section{Redes de produção periférica na economia criativa e impactos das inovações tecnológicas recentes na música}

As indústrias culturais e criativas ${ }^{5}$ utilizam componentes culturais em seus processos, dependentes da história e cultura local, o que acarreta heterogeneidade nos processos e produtos decorrentes das diferenças locais. Soma-se a isso, a importância de relações entre diferentes setores das indústrias criativas (a relação entre música e cinema, por exemplo; ou ainda publicidade e audiovisual), que também contribui para a constituição dessas diferenças. Diante disso, podemos compreender as indústrias criativas como sendo sistemas abertos na concepção de Beinhoker (2006) e Comunian (2011), uma vez que as produções nas indústrias criativas envolvem intera-

5 Entende-se por indústrias criativas o conjunto de atividades econômicas que apresentem, em seu processo criativo, o uso da criatividade como insumo básico ou prioritário. indústrias criativas. Bendassolli et al. (2009) listam quatro principais características das indústrias criativas: (1) o uso da criatividade como aspecto central das atividades, sendo entendida nas concepções de Hesmondhalgh (2002) como a capacidade que os indivíduos possuem de decifrar e manipular símbolos para gerar algo inovador; (2) a valorização da arte pela arte, uma vez que os fatores culturais e artísticos têm forte relevância no processo produtivo; (3) $\bigcirc$ intenso uso de tecnologias de informação, que possibilitam a descentralização das atividades; e (4) o uso de "equipes polivalentes" e diversas nas criações. 
ções entre diversos agentes pertencentes ao mesmo setor ou a setores distintos. Trata-se de interações não lineares, que podem ser permanentes ou temporárias e, por vezes, geram consequências em todo o sistema criativo. Tais interações são características de processos não estáticos, dinâmicos e não determinísticos. Devido à presença de fatores culturais, as relações existentes entre diferentes agentes podem envolver influências que modificam o bem ou serviço de maneira significativa, gerando assim, uma característica de sistema aberto, fora do equilíbrio, baseado em interações inter e intrassistemas.

Tornando-se um sistema aberto com relações entre os agentes, podemos dizer que as indústrias culturais e criativas podem ser compreendidas como redes, a partir do conceito de Beinhoker (2006) e em consonância com Potts et al. (2008). Os padrões relacionais são específicos em cada setor das indústrias criativas. A quantidade de atores, o número de relações e a distribuição do poder, também, podem ser distintos.

O conceito de rede é amplamente utilizado no presente trabalho. Defendemos que as indústrias criativas (e em específico a produção de música) sejam analisadas a partir da noção de redes, quando se busca compreender os mecanismos explicativos do funcionamento geral da produção, distribuição e consumo das mesmas. Nos setores criativos, a diversidade de agentes que são importantes ao processo produtivo pode extrapolar os limites conceituais do setor. Por exemplo, a produção musical pode sofrer grande influência de agentes de fora do setor, como profissionais do audiovisual e comunicação. A interconexão entre as indústrias criativas é premissa presente, e uma análise em rede permite captar esse fato.

As TICs foram protagonistas desse processo, uma vez que possibilitaram redução nos custos de produção democratizando o acesso a softwares para a produção de CDs e música digital. Com essa possibilidade, estúdios de gravação musical de menor porte surgiram, inclusive alguns home studios. Essa reconfiguração do setor levou a novas possibilidades de produção musical para a pequena produtora (em gravadoras indies ${ }^{6}$ ), assegurando novos meios de divulgação, consumo e uma nova janela de oportunidade

6 A esse grupo de gravadoras menores que apresentam um "produto diferenciado" direcionado a públicos específicos e menores convencionou-se chamar de 'gravadoras indies'. Apresentam um leque reduzido de artistas e opções (em relação às majors), geralmente são empresas focadas em um ou poucos estilos musicais. 
para competitividade com as grandes empresas (Wikstrom, 2009; Dolata, 2011; Watson, 2016; Tschmuck, 2016).

Analisando algumas consequências da digitalização da música, Wikström (2009) afirma que houve redução do controle do fluxo de informação pelos maiores players do mercado. Antes da digitalização, a informação apresentava um alto fluxo das empresas em direção à audiência, com conexões fracas no sentido inverso, o que ocasionava um poder às empresas em relação ao processo de informação e comunicação. Cabia a essas empresas a escolha dos meios de difusão, quantidade e público-alvo. Esse cenário mudou. Devido ao maior fluxo de informações, redução de custos e maior acessibilidade aos meios de gravação Wikström (2009) pontua ainda que outro impacto decorrente da digitalização da música (e da conectividade que a acompanha) é a maior presença de músicos e artistas "amadores" em relação aos "profissionais" no mercado. A conectividade permite que consumidores de música passem a produzir conteúdos musicais e carregar esses arquivos nas plataformas como YouTube, Soundclound, Myspace etc.

O fenômeno da digitalização na música é analisado também por Watson (2016), que aborda o impacto do que se denomina digital disruption no setor de produção/gravação de música. A partir da ascensão das tecnologias domésticas (e maior participação de agentes médios e pequenos no setor) e das modificações ocorridas no modo de produção e consumo, o autor afirma que as empresas de pequeno e médio porte passam a ser grandes expoentes do setor. Tschmuck (2016) também aborda o fenômeno e chega a conclusões similares. Afirma que as relações no mercado sofrem alterações, pois o peso das grandes empresas é diminuído, enquanto artistas e pequenos agentes são deslocados para os centros de decisões e participações.

Com base nisso, podemos dizer que, mais uma vez, as novas tecnologias no setor musical diminuem as barreiras à entrada no mercado. A possibilidade de participação no mercado é ampliada a músicos não experientes e independentes. Janelas de distribuição como o YouTube e as plataformas de streaming funcionam como uma entrada ao segmento de música de nicho, possibilitando maior visibilidade e possibilidade de contato com gravadoras e empresários do setor. $\bigcirc$ aumento da participação de "amadores" no mercado ocorre possibilitado pela tecnologia. Os agentes que estão espacialmente distantes de empresas gravadoras e dos grandes 
centros dispõem agora de ferramentas que possibilitam sua participação. Assim, presumimos que uma das consequências das novas tecnologias na produção musical é diversificar os locais de produção, alcançando outras regiões do território nacional e outros públicos.

Tais conclusões de Wikström (2009) também apresentam diálogo com a hipótese do trabalho. O autor afirma a maior participação de artistas amadores e de menor porte no mercado concorrendo com grandes artistas e players em geral. Esse fato gera, de acordo com ele, maiores possibilidades de inserção no mercado de trabalho. No entanto, devemos refletir sobre a realidade dessa suposta redução de barreiras à entrada. Talvez seja uma visão otimista e superficial falarmos em redução de barreiras à entrada, quando a própria tecnologia que causa a suposta redução não é ubíqua. As tecnologias de informação e comunicação, embora apresentem aumento em número de usuários, ainda são exclusivas de alguns grupos na sociedade global.

Assim, buscamos compreender o fenômeno do pequeno, local e independente. A música produzida em periferias urbanas tem a característica de ser independente em diversos aspectos: independência em relação às grandes gravadoras localizadas nos centros urbanos, à grande mídia e veículos de comunicação, e, por vezes, às políticas públicas culturais. Esse caso pode ser observado em algumas produções, especialmente o funk carioca, do tecnobrega paraense, da música rap produzida nas periferias de São Paulo, e também em outras cidades brasileiras como Brasília (Dayrell, 2002; Camargos, 2015).

A música é um dos produtos culturais mais consumidos e produzidos nas periferias urbanas. E esse produto é dividido em diferentes estilos musicais que formam grupos com intensos laços de amizade e profissionais, trocas de experiência e criação coletiva. Assim, a experiência de consumo e de criação musical nesses espaços gera uma rede de trocas sociais e, também, econômicas por esses agentes com uma identidade comum e, assim, o sentimento de pertencimento se constrói. Essa rede possui, então, características conceituais próximas à sociologia econômica, como também características próprias por se tratar de uma rede de criação cultural e criativa em zona periférica que as diferencia da forma como a produção cultural se dá nos lugares que representam o centro da produção.

Porém, as redes criativas diferem, em algum sentido, dos conceitos de redes da sociologia econômica, porque apresentam em sua composição 
fatores específicos de produção cultural que trazem singularidades ao seu funcionamento. As características de redes apresentadas por Powell (2003) como a comunicação baseada nas relações, as aptidões complementares balizadoras de normas, a reputação dos agentes como resolutórias de conflitos, incentivo para aprendizado, troca de experiências e conhecimento tácito existem nas redes criativas. Entretanto, fatores como a troca de serviços artísticos por outros serviços artísticos e a função colaborativa - que não envolvem trocas monetárias nas produções - também se fazem presentes. A produção e atuação dos agentes no sentido da arte pela arte diferencia essa rede criativa (e cultural) das demais redes econômicas definidas na literatura.

Assim, nas redes musicais discutidas por Leyshon (2014), podemos encontrar possibilidades de diálogo com os conceitos de Powell (2003) e outros autores da sociologia econômica. Entretanto, existem características próprias da produção musical que diferenciam as redes musicais das outras organizações em redes no sistema econômico. Os agentes se organizam através de relações de pré-produção e pós-produção para a construção de produtos e serviços musicais diversos para a comercialização e distribuição no mercado.

Embora o processo técnico de produção de música seja semelhante, quando analisamos diferentes espaços e territórios, as relações e, por consequência, a estrutura e o significado da rede são distintos. Como dito, a música em periferias urbanas é um instrumento de construção de identidade social, e esse fato acarreta em predicados específicos e únicos das redes de produção musical periféricas. Além do objetivo físico e material ou digital, ou seja, a produção do objeto cultural CD ou música digital, existe o objetivo da construção identitária e ampliação da atividade musical do território para a comunidade, dilatando assim o sentimento e a possibilidade de pertença dos moradores e indivíduos que frequentam o local. Os agentes envolvidos nessas redes musicais periféricas atuam, então, com intuito econômico, realizando trocas de bens e serviços por unidades monetárias, mas também com objetivo comunitário, realizando os mesmos serviços por valores menores ou ainda por trocas de favores alternativos.

Assim, na próxima seção, descrevemos os instrumentos utilizados para delineamento de uma rede de produção de rap no Grajáu, segundo arcabouço metodológico da Análise de Redes Sociais. 


\section{Aspectos metodológicos da construção da rede}

A análise de redes, metodologia deste estudo, se baseou em pesquisa de campo com questionário semiestruturado onde se questionam informações concernentes ao uso e impacto de tecnologias digitais, bem como às relações interpessoais. Para esse último aspecto, utilizamos de elementos da Análise de Redes Sociais (doravante ARS). Os dados são construídos a partir de coleta primária de informações sobre o rap na zona sul de São Paulo, especificamente o distrito de Grajaú. Dessa forma, pode-se entender que o trabalho está baseado na verificação das hipóteses levantadas a partir da análise do estudo de caso. Ou seja, o trabalho realiza a pesquisa de campo no intuito de responder às questões sobre o uso e impacto das tecnologias, bem como a forma estrutural da produção de rap na região do Grajaú em São Paulo. O primeiro passo foi delimitar os horizontes de alcance da pesquisa de campo para a aplicação dos questionário e construção das redes sociais, bem como determinar as unidades analíticas que são buscadas em campo. Em se tratando de entrevistas iniciais da pesquisa de campo, questiona-se sobre as relações que esses atores realizam.

The unit of observation is the entity on which measurements are taken. Most often social network data are collected by observing, interviewing, or questioning individual actors about the ties from these actors to other actors in the set. Thus, the unit of observation is an actor, from whom we elicit information about ties (Wasserman; Faust, 1994, p.43)

O primeiro limite (boundarie) ocorre em relação à delimitação urbana específica da atividade de produção da música rap no território analisado. A proposta analítica aqui é de compreender como se dá a relação de produção e o uso de tecnologia nas periferias urbanas, tendo como caso a zona sul de São Paulo. São, assim, incluídas apenas as unidades analíticas que estejam inseridas nesse território, ${ }^{7}$ a região analisada é a zona sul do município de São Paulo (especificamente a produção de rap no distrito do Grajaú).

$\mathrm{Na}$ busca de compreender esse limite, recorremos à obra de Rogério Haesbaert, que apresenta um enfoque do território baseado em três aspectos: a) jurídico-político: um espaço que recebe influência direta de um determinado poder (estatal); b) cultural: em um território existe uma

7 Por se tratar de análise de redes sociais, utilizando a técnica de amostragem de snowball, pode ser que algum dos entrevistados leve a agentes e atores que estejam fora do específico território que, são, posteriormente, incluídos na pesquisa. O limite espacial se dá em relação à produção de música e de estilo. 
priorização de aspectos simbólicos e subjetivos; o território pode ser compreendido como um produto da apropriação do imaginário ou da identidade sobre o espaço; e c) econômica: analisado em sua perspectiva material, de embate de classes e relações de capital-trabalho (Haesbaert, 2002). ${ }^{8}$

Baseando nessas definições de território, delimitamos as áreas analisadas traduzidas no aspecto cultural do território. Embora tenhamos selecionado um (ou mais) bairro(s) de análise dos objetos de estudo, ressaltamos que os limites são mais flexíveis do que os "bairros administrativos". Assim, na pesquisa de campo, entendemos que o bairro vizinho (não antes selecionado) pode se tornar parte desse território. $O$ bairro é um epicentro analítico, sabendo, entretanto, que o horizonte de território pode ser mais amplo. O segundo limite da pesquisa de campo diz respeito ao tipo de música realizada nesse território, sendo a música rap o alvo de pesquisa. Unidades analíticas que estejam no mesmo espaço urbano e produzam música em outros estilos não são considerados na amostra. Por fim, o terceiro limite se estendeu à função exercida pela unidade analítica na produção musical. $O$ foco nessa etapa encontrou-se na produção e difusão de música nas periferias selecionadas. Assim, num primeiro momento, identificaram-se quais os agentes estão envolvidos nessa produção. O RAP apresenta uma estrutura onde diversos agentes são envolvidos como artistas, MCs, estúdios de gravação, organizadores de batalhas de rimas, casas de shows e produtores musicais, porém outras funções são envolvidas no processo como artistas visuais para as artes de CDs e shows e outras funções podem ser encontradas em campo.

Uma vez definidas as unidades analíticas, realizou-se a coleta de dados em campo a partir da aplicação de questionários com os agentes específicos. ${ }^{9}$ Os instrumentos de coleta foram construídos com o intuito de obter as informações de todas as unidades possíveis de análise (pessoas físicas e jurídicas), com variáveis de atributos e relacionais. Para fins de descrição dos atributos pessoais e socioeconômicos, incluíram-se variáveis como sexo, idade, escolaridade, tamanho da empresa, tempo de atuação, renda etc.

8 A discussão acerca de espaço e território é muito mais ampla e complexa do que as ideias brevemente apresentadas. Aqui a preocupação reside em apenas delimitar os limites de atuação da pesquisa de campo a partir do conceito de território. Para maiores detalhes das definições, recomenda-se a leitura das obras referenciadas e também de trabalhos de Edward Soja, Henri Lefébvre, além de outras obras de Milton Santos e Rogério Haesbaert.

9 Os questionários podem ser socilitados através do e-mail rod.cmichel@gmail.com. 
Dois questionários foram elaborados: um voltado para músicos/artistas, e o outro, para agentes diversos, em especial empresários de empresas gravadoras, distribuidoras etc. No primeiro foram descritos atributos pessoais e socioeconômicos, bem como as questões relacionais. Os questionários foram divididos em blocos de questões para possibilitar melhor organização das variáveis. Cada bloco associa-se a uma problemática específica, porém o conjunto dos dados possibilitou uma análise mais detalhada do objeto. Estamos lidando, grosso modo, com o uso de tecnologias e a produção musical em um espaço periférico do município de São Paulo. Para compreender o fenômeno em completude, fez-se necessário o questionamento acerca de informações que possibilitem situar cada entrevistado (unidade de análise) em relação à condição social e econômica, à atuação musical e artística, ao uso tecnológico e, por fim, ao posicionamento e ao papel na rede social de produção de música rap.

De posse das informações descritas, a próxima etapa compreendeu a pesquisa de campo através da coleta e sistematização de informações da produção de música rap e o uso da tecnologia nas produções realizadas em zonas periféricas urbanas na zona sul de São Paulo. A seleção de entrevistados foi baseada a partir de pesquisa com especialistas nos assuntos, como músicos consolidados pelo público, e gravadoras de música rap de São Paulo.

Como salientado por Lazega e Higgins (2014), existe dificuldade de delimitação amostral da coleta de dados das variáveis relacionais e de atributos de uma rede. Os métodos de amostragem, se utilizados para a delimitação das observações a serem analisadas em uma ARS, pressupõem que, a partir de uma rede, seja possível extrair uma amostra que descreva a realidade da rede como um todo. Contudo, utilizar técnicas amostrais onde todos os indivíduos apresentem a mesma probabilidade de serem incluídos na amostra pode ser um problema, pois nem todos os atores apresentam a mesma função, grau relacional e outras características.

Assim, no processo amostral pode ser excluído um agente crucial na rede, que liga grupos de atores, por exemplo. Como uma forma de superar esses obstáculos os autores sinalizam para métodos amostrais que se valem de técnicas não probabilísticas, como o snowball sampling. Destarte, a amostra foi iniciada com rappers, MCs e grupos de rap de várias trajetórias na região, tanto aqueles já consolidados no mercado nacional, bem como expoentes na nova geração. Além disso, existem agentes de produção tam- 
bém antigos e novos no cenário do Grajaú. A heterogeneidade de atores escolhidos como seeds garantiu que as entrevistas fossem levadas a outros perfis de agentes, partindo do pressuposto de que os indivíduos tendem a ter relações mais próximas com agentes de capital social, cultural e econômico correlatos. $\bigcirc$ trabalho em campo contou, então, com a definição dos seeds para a amostra, considerando os instrumentos possíveis (pesquisas anteriores, websites, facebook) e buscando a heterogeneidade na seleção para minimizar vieses de seleção. Partindo desses agentes, pressupõe-se que a rede coletada apresentaria também uma diversidade de atores decorrentes dessa delimitação inicial, com o intuito de realizar inferências válidas acerca da produção musical nos territórios.

Em ARS, existem diferentes modelos analíticos, tais como redes sociométricas totais, redes egocentradas, redes de dois modos (ou filiação, ou two-mode), redes multiníveis e outros desenvolvimentos metodológicos. No presente estudo, optamos pelas redes sociométricas totais, pois buscamos compreender as relações estabelecidas entre agentes diversos como um todo.

As redes sociométricas totais são redes sem especificidades de agentes (tipos) e relações. ${ }^{10}$ Mostram todas as relações entre os agentes, apenas diferenciando-os por seus atributos, e buscam atingir a totalidade de agentes em uma rede. Assim, para o presente caso, os músicos, artistas, empresas e demais agentes são compreendidos como agentes. Então, nessa etapa da metodologia, buscamos responder como é a forma do mercado de produção do rap na região analisada. Quais são as etapas produtivas e as relações estabelecidas pelos músicos para a produção de um álbum. E ainda, analisamos se existem relações únicas dentro da rede, ou seja, se a região é caracterizada por um polo de produção local onde todos os agentes (ou a maioria) se relacionam entre si, ou se existem relações estabelecidas em grupos específicos (clusters). Na sequência, dividimos essa rede geral em duas redes correlatas, sendo $\left(A^{\prime}\right)$ a rede resultante das relações efetuadas que envolvam trocas monetárias e (A") a rede de "colaboração", apenas com as trocas não monetárias. $O$ objetivo dessa rede foi responder à indagação de que a forma produtiva que emerge na região após os adventos das TICs apresenta um aspecto colaborativo intenso. Pudemos aqui estabelecer as diferenças entre as duas redes e os agentes destacados em cada uma, assim como realizado na rede geral. Ou seja, o desenho de 
pesquisa e a técnica aqui empregados incorporam elementos essenciais da abordagem teórica ora utilizada e permite estabelecer as conexões entre os agentes e atores envolvidos, de forma a tratar de forma adequada a hipótese trazida.

\section{Redes de produção musical periféricas e os impac- tos da tecnologia nos agentes e em suas relações: resultados e discussões}

A amostra foi composta por 26 músicos e 4 empresários que atuam na produção musical no território do Grajaú. Esse número é justificado, pois de acordo com a técnica amostral apresentada não partimos de um número fixo nem de metas para o cálculo da amostra. Notamos o ponto de saturação a partir da $26^{a}$ entrevistas, pois as informações coletadas não apresentavam mais ineditismo e, assim, optamos por esse número. As entrevistas foram realizadas em dois períodos, o primeiro realizado entre os meses de abril e maio de 2016, e outubro e novembro de 2017.

A idade média é de 29,8 anos, sendo o mais jovem entrevistado de 19 anos, e o mais velho 41, indicando boa variabilidade. Todos os entrevistados são do sexo masculino. Além disso, verifica-se maior participação de indivíduos que se declaram como negro e pardo, com apenas $12 \%$ da amostra declarada como branco. Em relação à escolaridade, observou-se que que a maior parte da amostra é composta por indivíduos que concluíram o ensino médio (64\% das observações), e 16\% fizeram graduação No que tange à educação musical, cerca de $54 \%$ dos entrevistados afirmaram ter realizado algum tipo de curso.

O tempo de atuação no RAP enquanto agente ligado à produção de música é variável na amostra, nota-se que $56 \%$ das pessoas estão há mais de 10 anos no setor, enquanto $24 \%$ afirmam atuar no RAP desde um a cinco anos. Esses dados sugerem que a amostra conseguiu captar a heterogeneidade de agentes já estabelecidos e novatos no setor. Mais de $90 \%$ dos indivíduos afirmaram que a inserção no RAP se deu no bairro de moradia, evidenciando a existência de um cenário dinâmico da produção musical no local.

No que tange à inserção do trabalho artístico na cidade, 43\% afirmaram que a atuação até hoje é no bairro onde habitam no distrito de Grajaú; 
outros $40 \%$ registraram que sua atuação é dividida entre as periferias da cidade de São Paulo, como também no centro da cidade; os demais atuam com maior ênfase fora da cidade, na região metropolitana e outros estados. Em se tratando dessa atuação profissional das pessoas, verificamos que a maior parte dos indivíduos entrevistados considera a atividade no RAP como emprego secundário. Cerca de $80 \%$ possuem outro emprego, sendo que, desse montante, $25 \%$ realizam atividades ligadas às indústrias criativas como, por exemplo, produtor cultural, professor de hip-hop, tatuador e administração de galeria de arte. A remuneração por shows é a fonte de renda da atividade musical mais enunciada pelos entrevistados como principal, seguida por venda de produtos relacionados, como artigos de vestuário e adereços. Tanto a venda de CDs físicos como a remuneração através das plataformas de broadcasting e streaming foram citadas por apenas um entrevistado. Dessa forma, no sentido de remuneração pelo trabalho musical dos artistas analisados, a lógica segue a tendência da indústria fonográfica, em proporções menores. Assim como atualmente os grandes artistas mundiais auferem lucros através de shows, os artistas situados na periferia do Grajaú também encontram nas contratações de shows fonte de renda para a atividade musical.

CD hoje cada vez tá ficando mais difícil vender CD. A gente chegou até num
consenso de quando a gente faz show faz uma premiação, no palco ali distribui.
Porque acaba que você fica com material parado, e não compensa. Então se você
tá em outra área, cê cativa, cê fala: "dá uma escutada lá, depois você comenta,
entra na página". Daí fala de página, das redes sociais. Então é mais um cartão
de visita. A gente não espera mais grana do CD. A gente já insistiu nisso, numa
época anterior (Entrevistado A8).

Notamos, então, que a venda de unidades físicas de CDs e EPs representa uma oportunidade de maior visibilidade e divulgação do trabalho. O recurso de plataformas de música digital também se comporta da mesma forma, uma vez que poucos entrevistados afirmam conseguir recursos com essas ferramentas. Em suma, estamos diante de uma amostra que apresenta as seguintes características, em geral: o trabalho artístico-musical é a segunda ocupação com uma geração de incremento de renda pequena. A pesquisa conseguiu captar indivíduos novatos e veteranos na atuação no rap e assim, permite que possamos analisar informações de agentes que sentiram as mudanças das novas tecnologias durante sua atuação, bem como de agentes que iniciaram suas carreiras no novo cenário tecnológico. Dessa forma, as inovações tecnológicas, a digitalização da música, 
afetaram e têm afetado os entrevistados ao possibilitar uma nova forma de produção mais acessível em termos espaciais e econômicos (através da redução de custos).

\subsection{A rede de produção de rap no Grajaú: centralidades reforçadas pela tecnologia}

Primeiramente, apresentamos os resultados da rede geral, ou seja, aquela onde todas as relações são medidas e mostradas, não fazendo diferença entre relações que envolvem trocas monetárias ou não. A partir da compreensão dessa rede, pudemos identificar o tamanho da rede de produção do rap, baseada nos entrevistados, horizonte de alcance das atividades em relação a funções e territórios alcançados e estrutura relacional.

Ficou clara a importância que os entrevistados percebem na dinamização de um mercado de produção local, como forma de atuação no mercado musical e, além disso, notamos outras informações importantes como a criação e consolidação de uma rede de produção própria, que é capaz de produzir música, sentido identitário, sentido de coletividade e autonomia do Grajaú e da periferia. A ideia de movimentação e valorização dos trabalhos artísticos locais foi percebida nas entrevistas realizadas. Alguns entrevistados afirmaram a preferência em trabalhar com indivíduos do território, pois existe uma identificação e a realização em movimentar a cena local.

A Figura 1 apresenta a rede geral de produção do RAP. As cores representam a função exercida na rede. Indivíduos em vermelho representam rappers e músicos em geral, sendo que o vermelho mais escuro representa indivíduos que foram entrevistados diretamente na pesquisa de campo, enquanto vermelho mais claro são agentes citados por esses entrevistados. Observações em verde indicam agentes responsáveis por gravação, masterização, produção, fabricação de beats e DJs; indivíduos em azul realizam funções de design, audiovisual e artes gráficas, enquanto agentes em amarelo foram classificados em outras funções. As formas geométricas indicam a localização dos agentes, onde círculos representam o Grajaú, quadrados indicam agentes localizados em outros espaços do município de São Paulo, triângulos representam outras cidades, estados e países e, por fim, losangos indicam agentes com localização indefinida. $\bigcirc$ tama- 
nho das formas geométricas está relacionado ao grau de intermediação dos agentes, obtida através das estatísticas de betweeness.

\section{Figura 1 Rede geral de produção do rap no Grajaú}

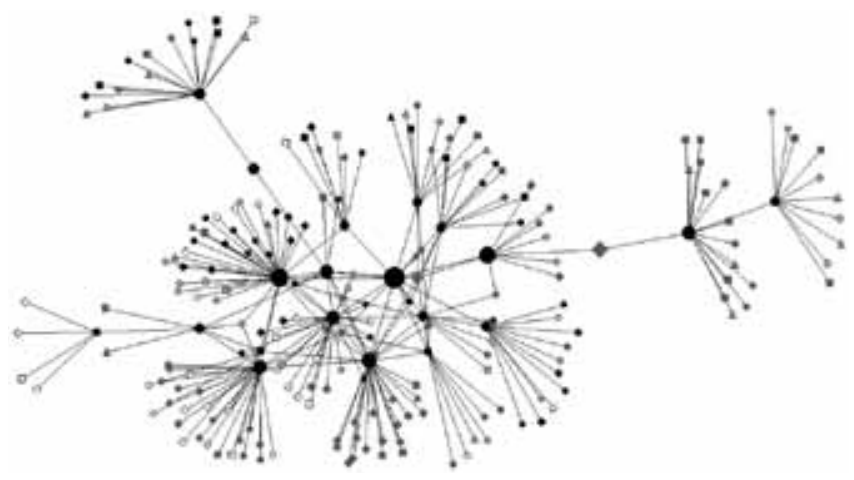

Fonte: Elaboração própria.

Legenda: Preto: rappers e músicos em geral; cinza-escuro: responsáveis por gravação, masterização, produção, fabricação de beats e DJs; cinza-claro: funções de design, audiovisual e artes gráficas, branco: outras funções. As formas geométricas indicam a localidade, círculos: Grajaú, quadrados: outros espaços do município de São Paulo, triângulos: outras cidades, estados e países e, por fim, losangos: agentes com localização indefinida.

A entrevista nos levou a uma rede composta por 230 atores. Cerca de $50 \%$ desses residem no distrito do Grajaú, 18\% em outras regiões da capital paulista, $7 \%$ outras cidades, estados e municípios, e cerca de $25 \%$ com localização indefinida. Esse fato evidencia que, embora se tratando de uma periferia urbana, a produção de música encontra diversos agentes locais no próprio distrito do Grajaú, porém estabelece diálogo com outras regiões do município bem como com outras cidades. Desses agentes, $22 \%$ foram classificados como rappers e músicos, $38 \%$ agentes produtores e gravadores, $17 \%$ trabalham com artes gráficas e/ou audiovisual, e 14\% atuam em funções classificadas como "outros". O restante da amostra corresponde aos agentes entrevistados em campo (rappers, DJs e produtores)

A densidade da rede geral da rede é de 0,010, indicando uma rede pouco densa, onde apenas $1 \%$ de todos os laços possíveis entre os agentes são estabelecidos. Esse baixo valor não surpreende, posto a metodologia de coleta dos dados relacionais. A pesquisa de campo captou informações acerca das relações exercidas pelos agentes entrevistados, não sendo possível es- 
tabelecer as relações entre os agentes citados por estes. Logo, não podemos levantar informações e conclusões acerca da densidade total da rede.

A distância média entre os agentes da rede é de 4,3 contatos, indicando que, perante a estrutura relacional da rede, para que um agente qualquer estabeleça relações com qualquer outro agente é preciso passar por 4,3 indivíduos. Essa estatística apresentou-se baixa, indicando facilidade de contatos na rede. Assim, as relações, indicações e reputações dos agentes nessa rede são importantes, pois, como os contatos são de fácil acesso, a troca de informações entre os agentes nela envolvidos é alta, facilitando o conhecimento da atuação e história pessoal entre eles.

Tabela 1 Estatísticas de centralidade na rede geral

\begin{tabular}{lrrrr}
\hline Agente & Intermediação & $\begin{array}{r}\text { Intermediação } \\
\text { normalizada }\end{array}$ & Grau \\
\hline A7 & 18.654 .938 & 37.346 & 15.000 \\
\hline A10 & 14.913 .010 & 29.855 & 39.000 \\
\hline A3 & 12.890 .900 & 25.807 & 10.000 \\
\hline A18 & 11.817 .079 & 23.657 & 31.000 \\
\hline A6 & 10.340 .000 & 20.700 & 16.000 \\
\hline A13 & 10.202 .692 & 20.425 & 28.000 \\
\hline B149 & 10.192 .000 & 20.404 & 2.000 \\
\hline A5 & 9.852 .552 & 19.724 & 28.000 \\
\hline A19 & 9.781 .632 & 19.582 & 11.000 \\
\hline B199 & 6.402 .000 & 12.816 & 2.000 \\
\hline A12 & 6.214 .000 & 12.440 & 15.000 \\
\hline A1 & 4.752 .000 & 9.513 & 13.000 \\
\hline B117 & 4.409 .452 & 8.827 & 6.000 \\
\hline A15 & 4.383 .987 & 8.776 & 14.000 \\
\hline A9 & 4.330 .000 & 8.668 & 11.000 \\
\hline A2 & 3.796 .558 & 7.600 & 12.000 \\
\hline A16 & 3.531 .901 & 7.071 & 11.000 \\
\hline A8 & 3.397 .931 & 6.802 & 7.000 \\
\hline A17 & 3.052 .000 & 6.110 & 9.000 \\
\hline A14 & 2.761 .643 & 5.529 & 12.000 \\
\hline A4 & 2.095 .491 & 4.195 & 7.000 \\
\hline A11 & 1.756 .000 & 3.515 & 5.000 \\
\hline
\end{tabular}

Fonte: Elaboração própria. 
Em relação à centralidade e importância dos agentes na rede geral, apresentamos as estatísticas de grau e intermediação dos principais agentes na Tabela 1. Os nomes dos agentes foram construídos da seguinte forma $\mathrm{A}(\mathrm{X})$ indica os indivíduos entrevistados diretamente na pesquisa de campo, enquanto $\mathrm{B}(\mathrm{X})$ são agentes que foram citados pelos entrevistados. $\mathrm{O}$ agente com maior grau de intermediação (A7), embora tenha trabalhos enquanto rapper e música, exerce primordialmente a função de produtor musical com um estúdio montado em sua residência. Esse agente foi citado por 15 indivíduos e respondeu estabelecer contatos com 8 indivíduos. $O$ segundo agente com maior intermediação (A10) atua como rapper solo e apresenta a maior rede pessoal entre os entrevistados, com 39 contatos.

Desse fato, pudemos observar que a possibilidade de criação de um home studio leva a atuações importantes na rede de produção. $O$ agente A6 apresenta a quinta intermediação mais elevada e também trabalha como produtor em um estúdio montado em sua residência. Assim, a possibilidade que as TICs trouxeram de construção dessas empresas de gravação no domicílio leva esses agentes a realizarem produções de artistas locais e a se caracterizarem como um ponto intermediador na rede, que conecta agentes de diversas funções.

\subsection{As trocas monetárias na produção de rap: a centralidade dos agentes de produção nas relações}

A produção de música rap no Grajaú envolve diversas relações, como visto na rede geral. O número de laços efetuados pelos entrevistados é variável, sendo que alguns entrevistados realizam seu trabalho com poucos parceiros e alguns criam redes de produção e criação mais abrangentes. Apresentamos nesta seção a rede de relações que envolvem apenas trocas monetárias entre os agentes.

Aqui nós temos vários profissionais, várias ramificações. Basta a gente se olhar, se valorizar, né? E fazendo essa troca, essa parceria, que eu acho maneiro. Envolve grana assim, que a gente tá se envolvendo, apostando num trabalho. Se isso repercutir, se isso tiver uma repercussão, eu acho justo partilhar, eu acho justo. O cara se dispôs a fazer o trampo, eu acho isso justo, tá ligado? Mas não é na base da troca, cê me dá isso eu te dou aquilo. Mas se acontecer, não tem porque não, tá ligado. Eu acho justo com o cara. Não é um profissional? Assim como eu quero ser entendido como um profissional? Eu tenho que respeitar o trabalho do cara, mano. Afinal, de contas, senão eu vou tá pensando só em mim, e como ficam as outras pessoas? (Entrevistado A5). 
As relações estabelecidas que envolvem trocas monetárias por bens e serviços para a produção de música no local podem ser observadas na Figura 2, que apresenta apenas as relações que compõem o que denominamos de rede monetária. Essa rede é composta por 106 agentes. Do total, cerca de $57 \%$ residem no Grajaú, 18\% em outras regiões da cidade de São Paulo, $7 \%$ em outras cidades, e 18\% apresentam localidade indefinida.

Da variedade dos agentes envolvidos, cerca de $42 \%$ dos atores desempenham função de produção e/ou gravação, representando a maior parte das relações monetizadas na rede de produção de música RAP; $15 \%$ atuam como atividades de artes gráficas e audiovisual; $5 \%$ são rappers e músicos (não entrevistados na pesquisa de campo) e participam como contribuições artísticas; $20 \%$ atuam em funções diversas que classificamos como "outros"; o restante da amostra é composto pelos agentes entrevistados em campo. Aqui se percebe uma diferença em relação à rede geral: no que condiz à distribuição das funções, a maior parte dos indivíduos que estabelecem relações monetárias são os produtores e gravadores, similar com a rede anterior, porém a participação de rappers e músicos nas relações monetárias é de apenas $5 \%$. Portanto, os indivíduos que possuem a tecnologia para a produção e gravação de músicas são os que mais detêm relações monetárias na rede de produção do Grajaú.

\section{Figura 2 Rede monetária}

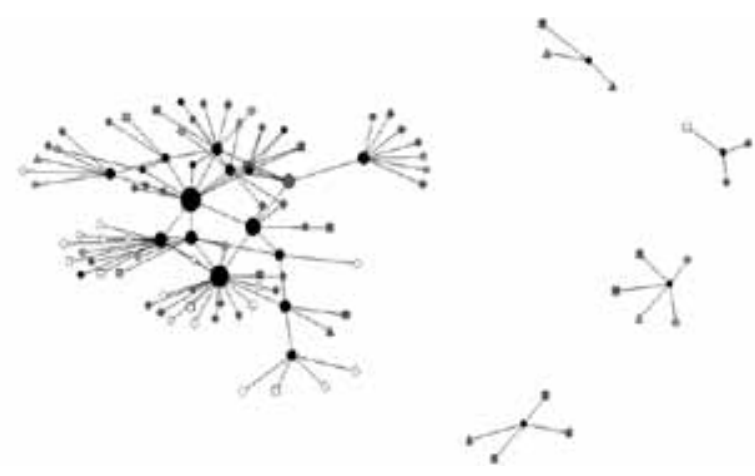

Fonte: Elaboração própria.

Legenda: Preto: rappers e músicos em geral; cinza-escuro: responsáveis por gravação, masterização, produção, fabricação de beats e DJs; cinza-claro: funções de design, audiovisual e artes gráficas, branco: outras funções. As formas geométricas indicam a localidade, círculos: Grajaú, quadrados: outros espaços do município de São Paulo, triângulos: outras cidades, estados e países e, por fim, losangos: 
agentes com localização indefinida.

A densidade da rede geral da rede é de 0,021, indicando, também, uma rede de baixa densidade, com apenas $2,1 \%$ de todos os laços possíveis de fato estabelecidos. Entretanto, devemos lembrar a observação sobre essa estatística quando analisamos a rede geral. A distância média entre os agentes da rede é de 2,19 contatos. Sendo menor do que a rede geral, o que é esperado, pois o número de agentes também é menor. Mais uma vez, notamos que as relações e reputações dos agentes são importantes, dada a possibilidade de fluxo de informações e facilidade de contatos entre os agentes.

Tabela 2 Estatísticas de centralidade na rede monetária

\begin{tabular}{lrrrr}
\hline Agente & Intermediação & $\begin{array}{r}\text { Intermediação } \\
\text { normalizada }\end{array}$ & Grau \\
\hline A7 & 3.197 .036 & 29.277 & 13.000 \\
\hline A5 & 3.137 .430 & 28.731 & 21.000 \\
\hline A18 & 1.998 .352 & 18.300 & 8.000 \\
\hline A13 & 1.512 .594 & 13.852 & 10.000 \\
\hline B117 & 1.454 .788 & 13.322 & 5.000 \\
\hline A10 & 1.364 .121 & 12.492 & 9.000 \\
\hline A8 & 1.129 .067 & 10.339 & 5.000 \\
\hline A3 & 1.120 .000 & 10.256 & 8.000 \\
\hline A15 & 1.038 .600 & 9.511 & 9.000 \\
\hline A16 & 1.004 .267 & 9.197 & 8.000 \\
\hline A14 & 810.000 & 7.418 & 7.000 \\
\hline A11 & 652.000 & 5.971 & 5.000 \\
\hline A4 & 559.636 & 5.125 & 4.000 \\
\hline A2 & 426.000 & 3.901 & 6.000 \\
\hline B159 & 246.000 & 2.253 & 1.000 \\
\hline A1 & 166.000 & 1.520 & 3.000 \\
\hline B116 & 63.255 & 0.579 & 2.000 \\
\hline A9 & 20.000 & 0.183 & 5.000 \\
\hline A6 & 12.000 & 0.11 & 4.000 \\
\hline A12 & 6.000 & 0.055 & 3.000 \\
\hline A17 & 6.000 & 0.055 & 3.000 \\
\hline B92 & 0.2 & 0.002 & 1.000 \\
\hline B175 & 0.2 & 0.002 & 1.000 \\
\hline f & & &
\end{tabular}

Fonte: Elaboração própria. 
A Tabela 2 mostra as estatísticas de Grau e Intermediação dos principais agentes na rede monetária. $O$ agente com maior grau de intermediação (A7) é o mesmo agente da rede geral. Esse agente foi citado treze vezes e respondeu estabelecer contatos com oito indivíduos. O segundo agente com maior intermediação na rede monetária (A5) é diferente da rede geral. Trata-se de um agente que atua como produtor e DJ na região, trabalhando com diversos agentes entrevistados em campo. $O$ quinto também é um produtor musical (B117). Notamos, portanto, que as transações monetárias levam os agentes produtores a se inserirem com maior poder na rede de relações.

\subsection{Relações colaborativas e as criações coletivas de músicos e artistas do rap no Grajaú}

A última rede a ser apresentada mostra as relações que não envolvem trocas monetárias entre os agentes. Trata-se de serviços artísticos ou não que envolveram a criação, produção, gravação de músicas, vídeos e outras funções ligadas à produção musical de rap no Grajaú. Embora essas relações não envolvam trocas monetárias, compreendemos que elas são baseadas na confiança mútua e na reputação criada na trajetória do indivíduo.

Na verdade, são outras coisas que fazem girar assim. É que cê fica com uma dívida de gratidão que ela fica uma coisa natural. Cê não precisa falar - oh, mano, cê tá me devendo depois cê paga - Num tem, quando cê tiver cê paga. Isso é uma coisa que já tá predefinida assim, transcendental. Ninguém precisa explicar isso, a gente sabe que as pessoas que ajudam as coisas acontecem (Entrevistado A1).

A rede colaborativa é composta por 157 agentes e pode ser observada na Figura 3. Cerca de $52 \%$ dos indivíduos residem no Grajaú, $15 \%$ em outras regiões da cidade, $6 \%$ em outras localidades, e o restante com localização indefinida. Quase 30\% dos agentes são músicos e rappers; 34\% desempenham função de produção, gravação e afins; $14 \%$ funções de artes gráficas e visuais, $10 \%$ em outras, e o restante da rede é composta pelos agentes entrevistados em campos. Observamos aqui a maior participação de músicos e rappers quando comparamos com a rede monetária. Assim, concluímos que as relações estabelecidas entre os músicos se dão no sentido de colaboração na criação de músicas e de participações em álbuns e faixas, não envolvendo trocas monetárias. Embora a participação seja de 
gravadores e produtores, é perceptível que, quando artistas e músicos se relacionam entre si, a probabilidade de essa relação não ser monetária é maior, sugerindo a colaboração artística.

\section{Figura 3 Rede colaborativa}

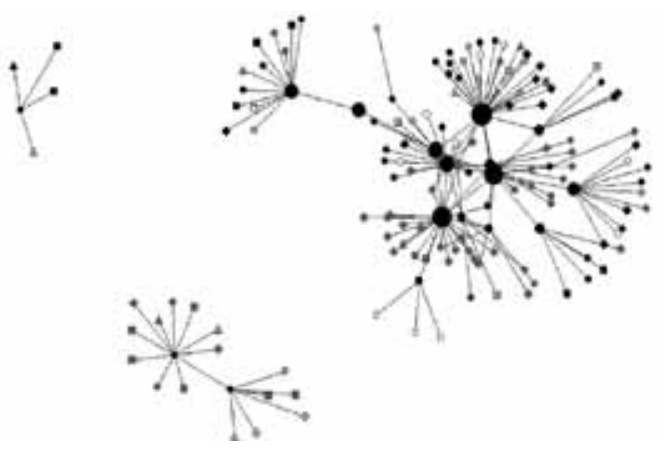

Fonte: Elaboração própria.

Legenda: Preto: rappers e músicos em geral; cinza-escuro: responsáveis por gravação, masterização, produção, fabricação de beats e DJs; cinza-claro: funções de design, audiovisual e artes gráficas, branco: outras funções. As formas geométricas indicam a localidade, círculos: Grajaú, quadrados: outros espaços do município de São Paulo, triângulos: outras cidades, estados e países e, por fim, losangos: agentes com localização indefinida.

Nota-se, assim, que a rede não monetária é maior do que as relações monetárias na produção de música RAP, indicando forte presença de aspectos colaborativos e comunitários no local. A quantidade de relações entre indivíduos residentes do Grajaú é similar nas redes econômicas e comunitárias, indicando que o mercado de produção local se sustenta econômica e comunitariamente. Assim, o mercado que se originou e se desenvolve a partir da tecnologia garante um fluxo econômico entre os agentes, mas também o fortalecimento das relações comunitárias, contribuindo para uma identidade musical local e coletiva.

A densidade da rede geral da rede é de 0,014 , o que caracteriza uma rede de baixa densidade com apenas $1,4 \%$ de todos os laços possíveis estabelecidos de fato. A distância média entre os agentes da rede é de 2,14 contatos, sendo muito similar à rede monetária. A Tabela 3 traz as estatísticas de grau e intermediação dos principais agentes na rede colaborativa. $\bigcirc$ agente com maior grau de intermediação (A10) é um rapper bastante conhecido e 
citado por boa parte dos agentes entrevistados na rede comunitária, bem como estabelece diversas relações. $O$ segundo agente com maior intermediação na rede colaborativa (A7) corresponde ao agente com maior grau de intermediação nas redes geral e econômica, mantendo também sua importância na rede colaborativa.

Tabela 3 Estatísticas de centralidade na rede colaborativa

\begin{tabular}{lrrrr}
\hline Agente & Intermediação & $\begin{array}{r}\text { Intermediação } \\
\text { normalizada }\end{array}$ & Grau \\
\hline A10 & 3.221 .650 & 26.647 & 32.000 \\
\hline A7 & 2.981 .567 & 24.661 & 13.000 \\
\hline A18 & 2.823 .917 & 23.357 & 28.000 \\
\hline A13 & 2.091 .167 & 17.297 & 21.000 \\
\hline A19 & 2.064 .683 & 17.078 & 8.000 \\
\hline B199 & 1.495 .000 & 12.366 & 2.000 \\
\hline A12 & 1.458 .000 & 12.060 & 13.000 \\
\hline A1 & 1.225 .000 & 10.132 & 11.000 \\
\hline A5 & 1.025 .067 & 8.479 & 11.000 \\
\hline A15 & 625.000 & 5.170 & 6.000 \\
\hline A17 & 502.000 & 4.152 & 6.000 \\
\hline A2 & 398.250 & 3.294 & 7.000 \\
\hline A4 & 378.000 & 3.127 & 4.000 \\
\hline A14 & 328.300 & 2.715 & 7.000 \\
\hline B91 & 204.400 & 1.691 & 4.000 \\
\hline A3 & 127.000 & 1.050 & 2.000 \\
\hline A8 & 127.000 & 1.050 & 2.000 \\
\hline A6 & 115.000 & 0.951 & 11.000 \\
\hline A9 & 81.000 & 0.67 & 7.000 \\
\hline B126 & 44.000 & 0.364 & 2.000 \\
\hline F & & & \\
\hline
\end{tabular}

Fonte: Elaboração própria.

Em resumo, podemos notar que o maior número de relações entres agentes entrevistados corresponde àquelas voltadas para as funções de gravação e produção de música nas três diferentes redes. Através das análises das entrevistas, percebemos que tais funções foram possibilitadas no território através das TICs (reduzindo custos e permitindo a produção "doméstica") e com o advento da internet. Tanto na rede geral como na rede 
monetária, o agente com maior intermediação corresponde a um produtor que possui um estúdio caseiro que afirmou ter adquirido o conhecimento de gravação através da internet. Na rede colaborativa, esse mesmo agente aparece como o segundo maior intermediador. Os rappers e músicos em geral apresentam baixa participação na rede monetária e alta participação na rede colaborativa, indicando que a troca monetária entre os agentes do Grajaú não se dá entre músicos, e sim em relações músicos-produtores; músicos-gravadores; artistas-artistas visuais.

Os resultados do estudo mostram que, embora o setor seja recorrentemente alvo de inovações tecnológicas desde seu princípio, as TICs trouxeram nova dinâmica ao setor, com alterações que, quando comparadas às tecnologias anteriores, proporcionam nova forma de atuação dos agentes, sejam estes músicos ou produtores. A redução de custos de produção e distribuição de música possibilitou ampliação do acesso às tecnologias de produção. Os entrevistados discorreram sobre tal fato a partir de suas experiências próprias, bem como da observação do comportamento de seus pares, evidenciando a importância da internet como forma de obtenção dos instrumentos produtivos (softwares e plataformas) e também como forma de obtenção de conhecimento técnico para essa produção. $O$ mesmo ocorre com a distribuição, uma vez que músicos e produtores atualmente dispõem da possibilidade de divulgação de seus trabalhos nas redes sociais, plataformas de streaming e broadcasting, bem como sites pessoais e outros. Assim, podemos dizer que, para a amostra analisada, as TICs trouxeram maior dinamização na produção de música a partir de maiores facilidades no acesso à produção. Nesse sentido, é possível creditar às novas tecnologias a inserção de novos atores no mercado da música, inclusive aqueles situados em zonas periféricas, além de ofertar mais facilidade de manutenção daqueles já consolidados no mercado.

A maior proximidade com os processos produtivos e tecnológicos trouxe aos artistas situados em zonas periféricas um modo de produção de música baseado nas relações locais. As redes construídas no presente trabalho mostram a preponderância de agentes locais (residentes no Grajaú e região) na produção e distribuição de música. O resultado são músicas, vídeos, e produtos derivados tipicamente do território em questão. A movimentação das relações segue uma tendência de privilegiar os laços comunitários. Essa tendência se sustenta tanto pelo respeito e pelas características de identidade como, também, por questões econômicas, pois, em 
algumas entrevistas, foi dito que os preços praticados pelos serviços de produção para os residentes são mais baixos.

Assim, caracterizamos a estrutura de produção de rap no Grajaú como intensa em aspectos colaborativos entre os músicos, com altas participações e reciprocidades entre eles, ao mesmo tempo que as relações monetárias são efetuadas com produtores e gravadores, beneficiados pelas TICs nas mudanças de processos produtivos.

\section{Considerações finais}

As inovações tecnológicas ocorrem no cerne do setor de produção musical desde sua gênese e geram impactos decorrentes em plurais aspectos: a) no formato do produto e, consequentemente, no modo de consumo; b) na estrutura de mercado, através de fusões e aquisições de empresas, surgimento de novas empresas e expulsão de outras, e; c) na forma de produção musical, com novas tecnologias e novos processos tecnológicos. Especificamente em relação a este último aspecto, novos processos tecnológicos levam a novas formas organizacionais e produtivas no interior do setor. Esses impactos se refletem, também, na redução de custos para a produção de música, bem como na descentralização da produção, uma vez que a produção doméstica é facilitada através dos home studios. O uso de análise de redes permite também observar como se dão os laços e como isso ajuda a criar esses impactos, entretanto, o desenho aqui utilizado nos leva a crer que, como tais laços são fortemente comunitários, eles sugerem uma restrição ao alcance de atores e instituições para além do Grajaú. No entanto, essa é uma hipótese a ser investigada em agenda de pesquisa futura. O que é certo são os impactos gerados pelas TICs no sentido de formato, processos produtivos, formas organizacionais e acesso à tecnologia. No caso analisado, percebemos que esses impactos chegam aos músicos e produtores situados na periferia em questão, alterando a forma de produção, distribuição e consumo. Permite-nos, também, observar como os artistas podem ser levados a se tornarem produtores e a se ligarem com consumidores que antes não alcançariam.

Para além dos resultados alcançados neste trabalho, sugerimos que, em potenciais trabalhos sobre segmentos da economia criativa, recorra-se a métodos como o de Análises de Redes Sociais por possibilitarem mapear 
as relações socioeconômicas em estruturas de produção e de distribuição de menor escala e de maior diferenciação de produto como o reportado neste estudo.

\section{Referências}

BEINHOCKER, E. D. The origin of wealth: Evolution, complexity, and the radical remaking of economics. [S.1.]: Harvard Business Press, 2006.

BENDASSOLLI, P. F. et al. Indústrias criativas: definição, limites e possibilidades. RAE-Revista de Administração de Empresas, Fundação Getulio Vargas, v. 49, n. 1, 2009.

CAMARGOS, R. Rap e política: percepções da vida social brasileira. São Paulo: Boitempo Editorial, 2015.

COMUNIAN, R. Exploring the role of networks in the creative economy of North East England: economic and cultural dynamics. In: Encounters and engagements between economic and cultural geography. Springer, Dordrecht, 2011. p. 143-157.

DAYRELL, J. O rap e o funk na socialização da juventude. Educação e pesquisa, v. 28, n. 1, p. 117-136, 2002.

DIAS, M. T. Os donos da voz: indústria fonográfica brasileira e mundialização da cultura. [S.I.]: Boitempo Editorial, 2000.

DOLATA, U. The music industry and the internet: A decade of disruptive and uncontrolled sectoral change. SOI Discussion Paper 2011-02, 2011.

HAESBAERT, R. Territórios alternativos. São Paulo: Contexto, 2002.

HESMONDHALGH, D. The cultural industries. London: Sage, 2002.

HERSCHMANN, M.; KISCHINHEVSKY, M. Indústria da música - uma crise anunciada. Trabalho apresentado ao NP, 2005.

LAZEGA, E.; HIGGINS, S. S. Redes sociais e estruturas relacionais. Belo Horizonte: Fino Traço Editora, 2014.

LEYSHON, A. Reformatted: Code, networks, and the transformation of the music industry. Oxford: Oxford University Press, USA, 2014.

NAKANO, D. et al. A produção independente e a desverticalização da cadeia produtiva da música. Gestão \& Produção, Universidade Federal de São Carlos, v. 17, n. 3, p. 627-638, 2010.

ORMEROD, P; POTTS, J; CUNNINGHAM, S; HARTLEY, J. Social network markets: A new definition of the creative industries. Journal of Cultural Economics, 32. 167-185. 10.1007/ s10824-008-9066-y, 2008

POTTS, Jason et al. Social network markets: a new definition of the creative industries. Journal of cultural economics, v. 32, n. 3, p. 167-185, 2008.

POWELL, W. Neither market nor hierarchy. The sociology of organizations: classic, contemporary, and critical readings, v. 315, p. 104-117, 2003. 
TSCHMUCK, P. From record selling to cultural entrepreneurship: The music economy in the digital paradigm shift. In: Business innovation and disruption in the music industry. Edward Elgar Publishing, 2016.

WASSERMAN, S.; FAUST, K. Social network analysis: Methods and applications. [S.1.]: Cambridge University Press, 1994.

WATSON, A. Digital disruption and recording studio diversification: Changing business models for the digital age. In: . Business innovation and disruption in the music industry. Edward Elgar Publishing, 2016.

WIKSTRÖM, P. The Music Industry: digital media and society series. [S.1.]: Cambridge: Polity Press, 2009.

\section{Sobre os autores}

Rodrigo Cavalcante Michel - rod.cmichel@gmail.com Doutor em Economia pelo Centro de Desenvolvimento e Planejamento Regional (Cedeplar) da Universidade Federal de Minas Gerais (UFMG). Belo Horizonte, Minas Gerais, Brasil.

ORCID: https://orcid.org/0000-0002-8962-9715.

Ana Flávia Machado - anaflaviatavaresmachado@gmail.com

Professora Associada da Faculdade do Centro de Desenvolvimento e Planejamento Regional (Cedeplar) da Universidade Federal de Minas Gerais (UFMG). Belo Horizonte, Minas Gerais, Brasil.

ORCID: https://orcid.org/0000-0001-8573-7906.

Natália Guimarães Duarte Sátyro - nsatyro@gmail.com

Professora Associada do Departamento e do Programa de Pós-Graduação de Ciência Política da Universidade Federal de Minas Gerais (UFMG), Belo Horizonte, Minas Gerais, Brasil.

ORCID: https://orcid.org/0000-0001-7298-342X.

\section{Sobre 0 artigo}

Recebido em 16 de outubro de 2019. Aprovado em 18 de fevereiro de 2020. 